\title{
Dietary fibre intake of pregnant women attending general practices in southern Brazil - The ECCAGE Study
}

\author{
Caroline Buss ${ }^{1, *}$, Maria Angélica Nunes ${ }^{1}$, Suzi Camey ${ }^{2}$, Patricia Manzolli ${ }^{1}$, Rafael \\ Marques Soares ${ }^{1}$, Michele Drehmer ${ }^{1}$, Andressa Giacomello ${ }^{1}$, Bruce Bartholow Duncan ${ }^{1}$ \\ and Maria Inês Schmidt ${ }^{1}$ \\ 'Federal University of Rio Grande do Sul, Graduate Studies Program in Epidemiology, UFRGS/Departamento de \\ Medicina Social/PPG-Epidemiologia, Rua Ramiro Barcelos n 2600 - $4^{\circ}$ andar - sala 419, CEP 90035-003, \\ Porto Alegre, Brazil: ${ }^{2}$ Federal University of Rio Grande do Sul, Statistics Department, Porto Alegre, Brazil
}

Submitted 21 February 2008: Accepted 6 October 2008: First published online 9 December 2008

\begin{abstract}
Background: Increase in fibre intake during pregnancy may reduce weight gain, glucose intolerance, dyslipidaemia, pre-eclampsia and constipation. Few studies have evaluated adequacy of fibre intake during pregnancy.

Objective: To assess, through an FFQ, the dietary fibre intake of pregnant women receiving prenatal care from general public practices and compare it with current guidelines.

Design and setting: Cross-sectional analyses of a pregnancy cohort study (ECCAGE - Study of Food Intake and Eating Behaviour in Pregnancy) conducted in eighteen general practices in southern Brazil, from June 2006 to April 2007.

Subjects: Five hundred and seventy-eight pregnant women with mean (SD) age of $24 \cdot 9(6 \cdot 5)$ years and mean gestational age of $24 \cdot 5(5 \cdot 8)$ weeks.

Results: The mean energy intake was $11615 \mathrm{~kJ} / \mathrm{d}(2776 \mathrm{kcal} / \mathrm{d})$. The mean total fibre intake $(30.2 \mathrm{~g} / \mathrm{d})$ was slightly above the recommended value of $28 \mathrm{~g} / \mathrm{d}$ $(P<0 \cdot 001)$, yet $50 \%(95 \%$ CI 46, 54) of the women failed to meet the recommendation. Whole-grain fibre constituted only $1 \%$ of total fibre intake in the cereal group. In adjusted Poisson regression analyses, not meeting the recommendation for fibre intake was associated with alcohol intake (prevalence ratio $1 \cdot 29 ; 95 \%$ CI $1 \cdot 11,1.50$ ) and absence of nutritional guidance (prevalence ratio $1 \cdot 22$; $95 \%$ CI $1 \cdot 05,1 \cdot 42$ ) during pregnancy.

Conclusions: About half of the pregnant women failed to meet the recommended fibre intake, especially those not reporting nutritional guidance during pregnancy. For most women, whole-grain cereal intake was absent or trivial. Taken together, our data indicate the need, at least in this setting, for greater nutritional education in prenatal care.
\end{abstract}

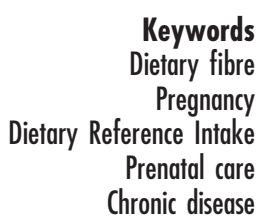

Nutrition is an important and modifiable determinant of non-communicable chronic diseases. Cumulative epidemiological evidence shows that a diet rich in fibre is associated with decreased risk of CVD, certain types of cancer and type 2 diabetes, as well as better weight management and glucose control ${ }^{(1-4)}$. In pregnancy, during which excessive weight gain is currently common ${ }^{(5)}$, additional benefits are a lower risk of pre-eclampsia ${ }^{(6,7)}$, abnormal glucose tolerance $^{(8)}$ and constipation ${ }^{(9,10)}$. A recent study also suggests an attenuation of pregnancy-associated dyslipidaemia by dietary fibre ${ }^{(7)}$.

Healthy eating habits of mothers also have importance beyond their own health because pregnancy is a critical period in the life of the newborn ${ }^{(11)}$. Additionally, mothers provide a role model for the eating patterns of the whole family ${ }^{(12)}$ and the mother's decisions about food are often made for the entire family. Since pregnancy represents a window for educating women about the benefits of healthy diet and lifestyle ${ }^{(13)}$, health professionals and in particular dietitians could use this period to encourage women to make lasting changes in their habits in order to improve not only pregnancy outcomes but also to reduce future chronic disease.

In Brazil, the Ministry of Health publication Nutritional Guidelines for Brazilians (2006) presents nutritional recommendations aiming to maintain healthy nutritional habits and prevent chronic diseases in adults ${ }^{(14)}$. This guide recommends a daily consumption of at least $25 \mathrm{~g}$ of dietary fibre, 3 servings of fruit and 3 servings of vegetables. During pregnancy, the recommendation for fibre 
intake, consistent with US recommendations, increases to 28 g daily $^{(15)}$.

Several studies in Brazil $^{(16-18)}$ and other countries ${ }^{(13,19-24)}$ describe the nutritional intake of pregnant women. Many of them studied specific populations (e.g. overweight and teenage women). To our knowledge, none of these studies evaluated dietary fibre intake during pregnancy in Brazil, a nation with a culinary culture considered to be based on fibre-rich foods, especially beans and fruits. Fruits and vegetables are important markers of a healthy diet for their high content of fibre, which contributes to satiety and displacement of higher energy-dense foods. Whole-grain foods are a privileged source of fibre for their phytochemical and antioxidant content compared with refined grains. Fibre intake from whole grains has been inversely associated with chronic disease and mortality ${ }^{(3,25)}$.

The aim of the present study was to assess, both quantitatively and qualitatively, the dietary fibre intake and factors associated with this intake in pregnant women receiving prenatal care in general practices in southern Brazil.

\section{Method}

\section{Design and setting}

ECCAGE - the Study of Food Intake and Eating Behaviour in Pregnancy - is a cohort study carried out in ten general public practices in Porto Alegre and eight general public practices in Bento Gonçalves, two cities in Rio Grande do Sul. Results presented herein pertain to the baseline data of ECCAGE. The study was approved by the ethics committee of the Federal University of Rio Grande do Sul and the committee responsible for the general practices in both cities. Written informed consent was obtained prior to all interviews.

\section{Subjects}

From June 2006 to April 2007, a total of 780 consecutive pregnant women between their 16th and 36th gestational weeks, receiving prenatal care in selected general practices covered by the study, were invited to participate during a routine prenatal care consultation. From these women, fifty-nine $(7 \cdot 5 \%)$ refused to participate and nine $(1 \cdot 1 \%)$ interrupted the interview prior to completion, resulting in a total of 712 pregnant women interviewed. Interviews were conducted before or after the clinical consultation; the principal reason given for refusal was lack of time to participate.

For the present analysis, 105 (14.7\%) women were excluded because their reported daily energy intake fell outside the usually accepted pregnancy range of $3347 \mathrm{~kJ}$ ( $800 \mathrm{kcal})$ to $20083 \mathrm{~kJ}$ ( $4800 \mathrm{kcal})$, based on the Institute of Medicine $(\mathrm{IOM})^{(26)}$ recommendations, as applied in previous studies ${ }^{(22,27)}$. Additionally, twenty-nine subjects
$(4.7 \%)$ were excluded for reporting a daily intake of fruit and vegetables greater than 16 servings $^{(28)}$, leaving 578 pregnant women for analysis.

\section{Data collection}

Interviews were conducted by trained interviewers. Weight and height were measured according to a standardized protocol and nutritional categories classified according to the IOM criteria $^{(29)}$. Data on sociodemographic variables were collected through a standardized questionnaire, with questions about age, marital status, years in school, family income, health-related behaviours such as tobacco and alcoholic beverage use during pregnancy, nutritional status before pregnancy according to self-reported $\mathrm{BMI}^{(29)}$, receipt of nutritional guidance, and number of meals consumed daily.

Data on food intake were collected through an 88-item FFQ, derived from a previously validated questionnaire $^{(30)}$ and validated for this population ${ }^{(31)}$. Pearson correlation coefficients obtained in the validation study of the FFQ against a $24 \mathrm{~h}$ food recall were 0.27 for energy and 0.42 for fibre intake. The questionnaire provided standard servings of each food item to assess the amount consumed during pregnancy. The subjects reported the number of servings and frequency of intake for each food item listed. This frequency was categorized as $>3$ times daily, 2 or 3 times daily, once daily, 5 or 6 times weekly, 2 to 4 times weekly, once weekly, 1 to 3 times monthly, and never or hardly ever.

\section{Analysis of food consumption data}

The estimated consumption of energy, fibre and servings of fruit and vegetables reported in the questionnaire was calculated as:

Number of servings consumed $\times$ Frequency of

consumption $\times$ Nutrient content of the food serving.

For these calculations, the following weights were assigned for the frequency of food consumption categories: ' $>3$ times daily' $=3$; ' 2 or 3 times daily' $=2$; 'once daily' $=1$; ' 5 or 6 times weekly' $=0.79$; '2 2 to 4 times weekly' $=0 \cdot 43$; 'once weekly' $=0 \cdot 14 ;$ ' 1 to 3 times monthly' $=0 \cdot 07$; and 'never/hardly ever' $=0$.

A nutrient database for different foods was constructed using two main Brazilian references ${ }^{(32,33)}$ and, when not listed, we used the information provided in food labels. Total dietary fibre in these references was determined using the Association of Analytical Communities (AOAC) methods ${ }^{(34,35)}$.

\section{Assessment of recommended food intake}

To evaluate the fibre intake of the subjects, the Adequate Intake for fibre intake in pregnancy as defined by the US Food and Nutrition Board, i.e. $28 \mathrm{~g} / \mathrm{d}$, was used ${ }^{(15)}$. To compare daily intake of fruit and vegetable servings with those currently recommended in Brazil, the servings listed 
in the questionnaire were converted to equivalents of the standard servings of the Nutritional Guidelines for Brazilians: at least 3 servings of fruit -1 serving equals $130 \mathrm{~g}$ of a food item in the group and contains $293 \mathrm{~kJ}$ ( $70 \mathrm{kcal})$, fruit juices not included; and 3 servings of vegetables -1 serving equals $60 \mathrm{~g}$ of a food item in the group and contains $63 \mathrm{~kJ}$ (15 kcal) daily ${ }^{(14)}$. Consistent with most guidelines, the Brazilian recommendation is that cereal intake should be primarily whole-grain cereal ${ }^{(14)}$. Therefore, a qualitative analysis of the fibre intake was performed to identify the percentage contribution of fibre from different food groups compared with the total fibre intake. The sources of dietary fibre were divided into cereals (refined and whole-grain), fruit, vegetables and legumes.

\section{Statistical analysis}

The percentage of pregnant women not meeting the recommendation was calculated. These and other descriptive analyses as well as those based on contingency tables were performed using the SPSS statistical software package version $13 \cdot 0$ (SPSS Inc., Chicago, IL, USA). The results are presented as means and standard deviations. The association between not meeting the recommended fibre intake and various factors was estimated adjusting for potential confounders with Poisson regression analysis using the STATA statistical software package version $9 \cdot 0$ (StataCorp, College Station, TX, USA). Variables with $P$ values lower than $0 \cdot 2$ in bivariate analyses were entered in multivariable modelling. Statistical significance was established at the two-sided 0.05 level.

\section{Results}

The mean (SD) energy intake was 11615 (3724) kJ/d (2776 $(890) \mathrm{kcal} / \mathrm{d})$. Mean daily intake of total dietary fibre was $30 \cdot 2(13 \cdot 4) \mathrm{g}$. A total of $290(50 \cdot 2 \%)$ women did not meet the recommendation for fibre intake.

As seen in the crude analyses of Table 1, not achieving the recommended fibre intake was associated with alcoholic beverage consumption $(P=0 \cdot 01)$; eating less frequently $(P<0 \cdot 001)$; not receiving nutritional guidance $(P=0.02)$; and having a higher pre-gestational BMI $(P=0 \cdot 04)$. The distribution of the variables of Table 1 was similar between those included and excluded from the sample (data not shown).

Figure 1 illustrates the contribution of different food groups as sources of fibre. Most of the fibre intake came from the cereal group $(10.5 \mathrm{~g} ; 35 \%$ of the total), but whole-grain consumption represented only $1 \%$ of this group intake. Approximately one-third of dietary fibre was supplied by the fruit group ( $10 \mathrm{~g} ; 34 \%$ ), followed by the legume group $(6 \mathrm{~g} ; 20 \%)$ and the vegetable group $(3.5 \mathrm{~g} ; 11 \%)$. Comparing the reported intake with the Nutritional Guidelines for Brazilians ${ }^{(14)}$, we identified that 213 (37\%; $95 \%$ CI 33, 41) pregnant women failed to meet the recommended fruit intake and 167 (29\%; 95\% CI 25, 33) failed to meet the recommended vegetable intake.

Table 2 explores the magnitude of the associations between sociodemographic and behavioural independent variables and not meeting the recommended fibre intake. Crude prevalence ratios are shown for variables presenting a $P$ value below $0 \cdot 2$. The multivariable model shows that the prevalence of not meeting the recommended fibre intake, adjusted for age, total energy intake, pre-gestational BMI and nutritional counselling, was 29\% higher in those consuming alcoholic beverages during pregnancy $(P=0 \cdot 001)$; and, once adjusted for the same variables and alcohol consumption, $22 \%$ higher in those not receiving nutritional guidance $(P=0 \cdot 008)$.

Table 3 explores the magnitude of similar associations with principal dietary factors. The adjusted prevalence ratio was $2 \cdot 07$ (95\% CI $1 \cdot 74,2 \cdot 46)$ for women not meeting the recommended energy intake; $1 \cdot 72$ (95\% CI $1 \cdot 49$, $1.98)$ for women not meeting the recommended legume intake; and $1.92(95 \%$ CI $1.65,2.25)$ for women not meeting the recommended fruit intake. In the multivariable model, after adjusting for all of these factors, meeting the recommended vegetable intake was no longer statistically significant.

To assess the degree to which exclusion of women with outlying quantities of intake altered the percentage of women not meeting recommended daily total fibre intake, we reanalysed this percentage. Without these exclusions, $294(41 \cdot 3 \%)$ women did not reach the recommended intake.

\section{Discussion}

In the present study of pregnant women receiving prenatal care in general public medical practices in southern Brazil, we found a mean daily dietary fibre intake of $30 \cdot 2 \mathrm{~g} / \mathrm{d}$, above the minimal recommended value. However, the intake of $50 \%$ of the sample was below this level, indicating the need for nutritional guidance. Moreover, the principal source of fibre was refined cereals.

The use of Dietary Reference Intakes to analyse individual intake ${ }^{(36,37)}$ has been questioned. These quantitative estimates of nutrient intake, published by the Food and Nutrition Board since 1998, were established for nutritional assessment and planning of groups of individuals. For instance, Murphy and colleagues ${ }^{(37)}$, in their recommendations regarding the use of Dietary Reference Intakes to assess adequacy of intake, state that comparison of mean intake of nutrients with an established value of Adequate Intake between groups is appropriate, and that a mean intake above the recommended value indicates a low prevalence of inadequacy.

However, physiological mechanisms ${ }^{(38)}$ - displacing available nutrients from the diet; requiring chewing, which slows down intake and promotes satiety; and 
Table 1 Sociodemographic characteristics, lifestyle habits and nutritional counselling of 578 pregnant women attending general medical practices in southern Brazil, 2006-2007

\begin{tabular}{|c|c|c|c|c|c|}
\hline \multirow[b]{2}{*}{ Variable } & \multicolumn{2}{|c|}{ Overall } & \multicolumn{2}{|c|}{ Subjects with fibre intake $<28 \mathrm{~g} / \mathrm{d}$} & \multirow[b]{2}{*}{$P^{*}$} \\
\hline & $n$ & $\%$ & $n$ & $\%$ & \\
\hline Age (years) & & & & & 0.133 \\
\hline$<19$ & 138 & $23 \cdot 9$ & 64 & $22 \cdot 1$ & \\
\hline $20-29$ & 295 & $51 \cdot 0$ & 143 & $49 \cdot 3$ & \\
\hline$>30$ & 145 & $25 \cdot 1$ & 83 & $28 \cdot 6$ & \\
\hline Living with partner & & & & & 0.438 \\
\hline Yes & 465 & $80 \cdot 5$ & 237 & $81 \cdot 7$ & \\
\hline No & 113 & $19 \cdot 5$ & 53 & $18 \cdot 3$ & \\
\hline Years of school attendance & & & & & $0 \cdot 859$ \\
\hline $0-4$ & 75 & $13 \cdot 0$ & 36 & $12 \cdot 4$ & \\
\hline $5-8$ & 283 & $49 \cdot 0$ & 145 & $50 \cdot 0$ & \\
\hline$\geq 9$ & 220 & $38 \cdot 0$ & 109 & $37 \cdot 6$ & \\
\hline Family income (minimum wages)† & & & & & $0 \cdot 848$ \\
\hline$<1$ & 102 & $17 \cdot 6$ & 50 & $17 \cdot 2$ & \\
\hline $1-3$ & 293 & $50 \cdot 7$ & 145 & $50 \cdot 0$ & \\
\hline$>3$ & 183 & $31 \cdot 7$ & 95 & $32 \cdot 8$ & \\
\hline Smoking during pregnancy & & & & & 0.375 \\
\hline Yes & 110 & $19 \cdot 0$ & 51 & $17 \cdot 6$ & \\
\hline No & 468 & $81 \cdot 0$ & 239 & $82 \cdot 4$ & \\
\hline Alcohol intake during pregnancy & & & & & 0.012 \\
\hline Yes & 97 & $16 \cdot 8$ & 60 & $20 \cdot 7$ & \\
\hline No & 481 & $83 \cdot 2$ & 230 & $79 \cdot 3$ & \\
\hline Number of meals consumed daily including snacks & & & & & $<0.001$ \\
\hline$<3$ & 33 & $5 \cdot 7$ & 25 & $8 \cdot 6$ & \\
\hline $3-5$ & 435 & $75 \cdot 3$ & 225 & $77 \cdot 6$ & \\
\hline$>5$ & 110 & $19 \cdot 0$ & 40 & $13 \cdot 8$ & \\
\hline Nutritional guidance in pregnancy & & & & & 0.015 \\
\hline Yes & 244 & $42 \cdot 2$ & 108 & $37 \cdot 2$ & \\
\hline No & 334 & $57 \cdot \overline{8}$ & 182 & $62 \cdot \overline{8}$ & \\
\hline Pre-gestational BMI $\left(\mathrm{kg} / \mathrm{m}^{2}\right) \ddagger$ & & & & & 0.043 \\
\hline$<19 \cdot 8$ & 68 & $11 \cdot 8$ & 27 & $9 \cdot 4$ & \\
\hline $19 \cdot 8-26$ & 353 & $61 \cdot 5$ & 174 & $60 \cdot 4$ & \\
\hline$>26-29$ & 68 & $11 \cdot 8$ & 34 & $11 \cdot 8$ & \\
\hline$>29$ & 85 & $14 \cdot 9$ & 53 & $18 \cdot 4$ & \\
\hline Total energy intake $(\mathrm{kJ}(\mathrm{kcal}) / \mathrm{d})$ & & & & & $<0.001$ \\
\hline$<10460(2500)$ & 236 & $40 \cdot 8$ & 191 & $65 \cdot 9$ & \\
\hline$\geq 10460(2500)$ & 342 & $59 \cdot 2$ & 99 & $34 \cdot 1$ & \\
\hline Total & 578 & 100 & 290 & 100 & \\
\hline
\end{tabular}

${ }^{*}$ Pearson $\chi^{2}$ test comparing those who met $v$. did not meet recommendations.

tMinimum wage in Brazil in $2006=$ US $\$ 175 \cdot 00 /$ month.

$\ddagger$ According to the Institute of Medicine ${ }^{(29)} ; n 574$ due to missing data on pre-gestational body weight.

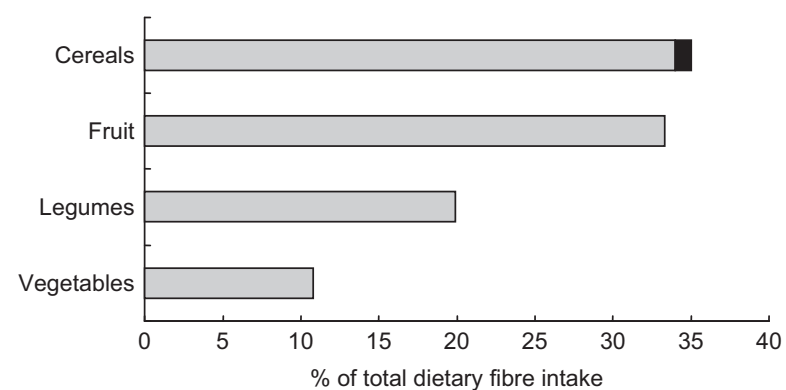

Fig. 1 Contribution of different food groups ( $\mathbf{\square}$, whole-grain cereal) as sources of dietary fibre among 578 pregnant women attending general medical practices in southern Brazil, 2006-2007

reducing the absorptive efficiency of the small intestine by which gram quantities of dietary fibre are thought to protect against disease are quite different from those by which microgram quantities of diverse micronutrients such as vitamins and trace minerals exert their beneficial effects. As such, while assessment of nutritional adequacy in groups by mean values may be the most appropriate approach for micronutrients such as vitamins, we believe that they are not for fibre.

Therefore we believe that our finding of $50 \%$ of women with intake below the cut point indicates an important prevalence of inadequate fibre intake. Our finding is all the worse given that the overall energy consumption of our sample, which contributes to total fibre intake, was above that recommended by the $\mathrm{IOM}^{(29)}$ of $10460 \mathrm{~kJ} / \mathrm{d}(2500 \mathrm{kcal} / \mathrm{d})$ for the second and third trimesters of gestation. Another recent study of Brazilian pregnant women ${ }^{(39)}$ reported a similar finding: $12088 \mathrm{~kJ} / \mathrm{d}$ $(2889 \mathrm{kcal} / \mathrm{d})$. Part of the present obesity epidemic results from excess weight gain in pregnancy, documented to be frequent in Brazil ${ }^{(5,40)}$. Thus, increased fibre content must be achieved in conjunction with a reduction in overall energy intake. 
Table 2 Factors associated with not meeting the recommended fibre intake in 578 pregnant women attending general medical practices in southern Brazil, 2006-2007

\begin{tabular}{|c|c|c|c|c|c|c|}
\hline & Crude PR & $95 \% \mathrm{Cl}$ & $P$ & Adjusted* PR & $95 \% \mathrm{Cl}$ & $P$ \\
\hline \multicolumn{7}{|c|}{ Pre-gestational BMI $\left(\mathrm{kg} / \mathrm{m}^{2}\right) \dagger$} \\
\hline$<19 \cdot 8$ & $0 \cdot 80$ & $0 \cdot 59,1 \cdot 10$ & $0 \cdot 174$ & 0.90 & $0 \cdot 70,1 \cdot 17$ & $0 \cdot 441$ \\
\hline $19 \cdot 8-26$ & $1 \cdot 00$ & ref & & $1 \cdot 00$ & ref & \\
\hline$>26-29$ & $1 \cdot 01$ & $0.78,1 \cdot 31$ & 0.914 & 0.96 & $0 \cdot 78,1 \cdot 19$ & 0.724 \\
\hline$>29$ & $1 \cdot 26$ & $1.04,1.54$ & 0.019 & $1 \cdot 12$ & $0.93,1.34$ & 0.225 \\
\hline \multicolumn{7}{|c|}{ Alcoholic beverage intake during pregnancy } \\
\hline No & $1 \cdot 00$ & ref & & $1 \cdot 00$ & ref & \\
\hline Yes & $1 \cdot 29$ & $1 \cdot 08,1.55$ & 0.006 & $1 \cdot 29$ & $1 \cdot 11,1 \cdot 50$ & 0.001 \\
\hline \multicolumn{7}{|c|}{ Nutritional guidance } \\
\hline Yes & $1 \cdot 00$ & ref & & 1.00 & ref & \\
\hline No & $1 \cdot 23$ & $1 \cdot 04,1 \cdot 46$ & 0.018 & $1 \cdot 22$ & $1 \cdot 05,1 \cdot 42$ & 0.008 \\
\hline
\end{tabular}

PR, prevalence ratio; ref, referent category.

*Through Poisson regression analysis adjusted for age, total energy intake and the other variables in the table.

tAccording to the Institute of Medicine ${ }^{(29)} ; n 574$ due to missing data on pre-gestational body weight.

Table 3 Dietary factors associated with not meeting the recommended fibre intake in 578 pregnant women attending general medical practices in southern Brazil, 2006-2007

\begin{tabular}{|c|c|c|c|c|c|c|}
\hline & Crude PR & $95 \% \mathrm{Cl}$ & $P$ & Adjusted* PR & $95 \% \mathrm{Cl}$ & $P$ \\
\hline \multicolumn{7}{|c|}{ Recommended energy intake $\dagger$} \\
\hline Greater than & 1.00 & ref & & $1 \cdot 00$ & ref & \\
\hline Lesser than & $2 \cdot 79$ & $2 \cdot 34,3 \cdot 34$ & $<0.001$ & $2 \cdot 07$ & $1 \cdot 74,2 \cdot 46$ & $<0.001$ \\
\hline \multicolumn{7}{|c|}{ Recommended legume intakeł } \\
\hline Yes & $1 \cdot 00$ & ref & & 1.00 & ref & \\
\hline No & $2 \cdot 03$ & $1 \cdot 73,2 \cdot 40$ & $<0.001$ & $1 \cdot 72$ & $1 \cdot 49,1 \cdot 98$ & $<0.001$ \\
\hline \multicolumn{7}{|c|}{ Recommended vegetable intakeł } \\
\hline Yes & $1 \cdot 00$ & ref & & $1 \cdot 00$ & ref & \\
\hline No & $1 \cdot 41$ & $1 \cdot 20,1 \cdot 65$ & $<0.001$ & $1 \cdot 07$ & $0 \cdot 93,1 \cdot 22$ & 0.360 \\
\hline \multicolumn{7}{|c|}{ Recommended fruit intake $\ddagger$} \\
\hline Yes & $1 \cdot 00$ & ref & & $1 \cdot 00$ & ref & \\
\hline No & $2 \cdot 53$ & $2 \cdot 15,2 \cdot 98$ & $<0.001$ & $1 \cdot 92$ & $1 \cdot 65,2 \cdot 25$ & $<0.001$ \\
\hline
\end{tabular}

PR, Prevalence Ratio; ref, referent category.

*Through Poisson regression analysis adjusted for the other variables in the table.

tAccording to the Institute of Medicine ${ }^{(29)}$.

$\ddagger$ According to the Nutritional Guidelines for Brazilians ${ }^{(14)}$.

The inadequacy of fibre intake in pregnancy we describe is not exclusive to southern Brazil. The mean daily fibre intake of our sample was two- to three-fold higher than in recent American ${ }^{(7,19)}$ and British samples ${ }^{(23)}$.

Nutritional education in routine prenatal care is a useful tool in the management of weight gain during pregnancy $^{(41,42)}$. Advice about the energy density of foods is essential to avoid excessive weight gain, with foods rich in fibre being a critical part of this recommendation.

Given the lack of Brazilian studies assessing dietary fibre intake in pregnancy, we additionally contrasted the reported fruit and vegetable intake with recommendations of the Nutritional Guidelines for Brazilians, published in $2006^{(14)}$. That $30-40 \%$ of our sample did not achieve the recommended intake is in consonance with a recent national survey which estimates that a three-fold increase in consumption of these food items is necessary to meet recommended intake ${ }^{(43)}$

Our results also document the importance of consumption of legumes and fruits, which together furnished approximately half of total fibre intake. Indeed, consumption of beans has decreased considerably over the years in Brazil, and nutritional guidance should emphasize the nutritional value and low cost of this foodstuff. Fruits are somewhat more expensive, but again, strategies exist to increase availability and consumption of fruits, even among those with limited incomes.

The qualitative analysis of fibre intake showed that whole-grain cereals made up only $1 \%$ of fibre intake from cereals. Several studies support the protective effect of whole-grain cereals against chronic diseases and mortality $^{(3,25,44)}$ and the consumption of most cereals as whole grains is a unanimous recommendation of nutrition guidelines. Our study thus emphasizes the distance between recommendation and reality in this regard, drawing attention to the importance of assessment and counselling concerning this most appropriate source of dietary fibre.

Our finding that receiving nutritional guidance was positively associated with meeting the recommendation for fibre intake emphasizes the role of the dietary counselling in prenatal care. Currently, nutritional guidance is 
not routinely structured within prenatal care in Brazil, leading to considerable variation in counselling across different practice settings. Greater efforts to educate pregnant women about fibre intake benefits and appropriate sources and quantity of dietary fibre might thus be of benefit.

Additionally, as those drinking alcoholic beverages were less likely to meet the fibre recommendation, poor dietary fibre intake may be part of a pattern of unhealthy behaviour. As this was an observational study, it is possible that women seeking healthy habits sought more dietary advice, avoided alcohol consumption and consumed greater quantities of fibre-rich foodstuffs.

Our study has limitations. It was not designed to be representative of pregnant women in the cities studied. On the other hand, we know of nothing particularly different in our sample from pregnant women in general seeking care at public primary care units in southern Brazil, and representative studies have not yet been undertaken. Another limitation is the important fraction of women excluded from analyses. Excluded subjects showed no important differences in basic sociodemographic criteria, thus minimizing risk of serious bias. Exclusion of women reporting extremes of total energy or fruit and vegetable intake probably led to some underestimation of total daily fibre intake. Yet, even with their inclusion, the percentage of women reporting inadequate intake was $41 \%$, still a large fraction of the sample. The true fraction of inadequate total daily fibre intake thus probably lies somewhere between $41 \%$ and $50 \%$.

The difficulty in estimating food consumption accurately and precisely in epidemiological studies is also a limitation. No method exists which is capable of measuring dietary intake flawlessly in large samples. FFQ such as ours are widely used to assess habitual diet in epidemiological research, including that in pregnancy $^{(13,20,22,45)}$, given their ability to classify individual eating patterns, their ease of administration and their relatively low cost. That we had previously validated the questionnaire used in the present study against $24 \mathrm{~h}$ dietary recalls of pregnant women for this population increased its accuracy and precision.

The present study can contribute to clinical practice by drawing attention to an important issue in nutritional prenatal care - low dietary fibre intake. Few studies of nutritional intake in pregnancy have assessed dietary fibre intake within the context of the nutritional transition in low- and middle-income countries. Greater attention should be given to consumption of dietary fibre in order to improve the profile of food intake, providing greater nutritional density, i.e. more nutrients per kilojoule consumed, while augmenting satiety. The assessment of food habits in pregnancy is fundamental to guide nutritional education. Health policies should emphasize the importance of a healthy diet in pregnancy and encourage a more appropriate level of dietary fibre intake.

\section{Conclusions}

Approximately half of pregnant women studied did not meet the cut point of $28 \mathrm{~g} / \mathrm{d}$ used as a recommendation for dietary fibre intake. Receiving nutritional guidance and greater ingestion of legumes and fruits were positively associated with reaching this cut point. The greatest source of dietary fibre intake was refined cereals, with whole-grain cereal providing a trivial percentage of fibre intake. Specific guidance in prenatal care nutritional counselling is needed regarding fibre intake in order to maximize short-term health benefits for pregnant women and long-term prevention of chronic disease.

\section{Acknowledgements}

This submission represents original work and has not been published previously. It is not currently being considered by another journal, and following acceptance for Public Health Nutrition will not be published elsewhere in the same form, in English or in any other language, without the written consent of the Nutrition Society. Each author has seen and approved the contents of the submitted manuscript. The authors have no conflict of interest.

Contribution of each author to the manuscript: The data reported in the present article were collected as part of the first author's MS dissertation that was supervised by M.A.N., S.C. and M.I.S. All authors were responsible for the design and performance of the ECCAGE Study. C.B. was responsible for the dietary assessment. C.B. and S.C. analysed the data. C.B., B.B.D. and M.I.S. wrote the paper with contributions from the other co-authors.

Sources of funding: Centers of Excellence Grant of CNPq (the Brazilian National Council of Technological and Scientific Development); CAPES/MEC (the Brazilian Ministry of Education).

\section{References}

1. Lindstrom J, Peltonen M, Eriksson JG, Louheranta A, Fogelholm M, Uusitupa M \& Tuomilehto J (2006) Highfibre, low-fat diet predicts long-term weight loss and decreased type 2 diabetes risk: the Finnish Diabetes Prevention Study. Diabetologia 49, 912-920.

2. American Dietetic Association (1997) Position of the American Dietetic Association: Health implications of dietary fiber. J Am Diet Assoc 97, 1157-1159.

3. Jacobs DR Jr, Meyer KA, Kushi LH \& Folsom AR (1998) Whole-grain intake may reduce the risk of ischemic heart disease death in postmenopausal women: the Iowa Women's Health Study. Am J Clin Nutr 68, 248-257.

4. Bhargava A (2006) Fiber intakes and anthropometric measures are predictors of circulating hormone, triglyceride, and cholesterol concentrations in the women's health trial. J Nutr 136, 2249-2254.

5. Nucci LB, Schmidt MI, Duncan BB, Fuchs SC, Fleck ET \& Santos Britto MM (2001) Nutritional status of pregnant 
women: prevalence and associated pregnancy outcomes. Rev Saude Publica 35, 502-507.

6. Frederick IO, Williams MA, Dashow E, Kestin M, Zhang C \& Leisenring WM (2005) Dietary fiber, potassium, magnesium and calcium in relation to the risk of preeclampsia. J Reprod Med 50, 332-344.

7. Qiu C, Coughlin KB, Frederick IO, Sorensen TK \& Williams MA (2008) Dietary fiber intake in early pregnancy and risk of subsequent preeclampsia. Am J Hypertens 21, 903-909.

8. Tovar A, Must A, Bermudez OI, Hyatt RR \& Chasan-Taber L (2008) The impact of gestational weight gain and diet on abnormal glucose tolerance during pregnancy in Hispanic women. Matern Child Health J (Epublication ahead of print version).

9. Jewell DJ \& Young G (2001) Interventions for treating constipation in pregnancy. Cochrane Database Syst Rev issue 2, CD001142.

10. Anderson AS \& Whichelow MJ (2005) Constipation during pregnancy: dietary fibre intake and the effect of fibre supplementation. Hum Nutr Appl Nutr 39, 202-207.

11. Barker DP (1998) Mothers, Babies and Health in Later Life. Edinburgh: Churchill Livingstone.

12. Symon AG \& Wrieden WL (2003) A qualitative study of pregnant teenagers' perceptions of the acceptability of a nutritional education intervention. Midwifery 19, 140-147.

13. Olson CM (2005) Tracking of food choices across the transition to motherhood. J Nutr Educ Behav 37, 129-136.

14. Ministério da Saúde, Brasil (2006) Guia alimentar para a população brasileira: promovendo a alimentação saudável. Brasília: Ministério da Saúde.

15. Food and Nutrition Board (2005) Dietary Reference Intakes for Energy, Carbohydrate, Fiber, Fat, Fatty Acids, Cholesterol, Protein, and Amino Acids. Washington, DC: National Academy Press.

16. Barros DC, Pereira RA, Gama SG \& Leal MC (2004) O consumo alimentar de gestantes adolescentes no Município do Rio de Janeiro. Cad Saude Publica 20, Suppl. 1, S121-S129.

17. Nascimento E \& Souza SB (2002) Avaliação da dieta de gestantes com sobrepeso. Rev Nutr 15, 173-179.

18. Azevedo DV \& Sampaio HA (2003) Consumo alimentar de gestantes adolescentes atendidas em serviço de assistência pré-natal. Rev Nutr 16, 273-280.

19. Giddens JB, Krug SK, Tsang RC, Guo S, Miodovnik M \& Prada JA (2000) Pregnant adolescent and adult women have similarly low intakes of selected nutrients. J Am Diet Assoc 100, 1334-1340.

20. Harley K, Eskenazi B \& Block G (2005) The association of time in the US and diet during pregnancy in low-income women of Mexican descent. Paediatr Perinat Epidemiol 19, 125-134.

21. Andersen LT, Thilsted SH, Nielsen BB \& Rangasamy S (2003) Food and nutrient intakes among pregnant women in rural Tamil Nadu, South India. Public Health Nutr 6, 131-137.

22. George GC, Hanss-Nuss H, Milani TJ \& Freeland-Graves JH (2005) Food choices of low-income women during pregnancy and postpartum. J Am Diet Assoc 105, 899-907.

23. Rees GA, Doyle W, Srivastava A, Brooke ZM, Crawford MA \& Costeloe KL (2005) The nutrient intakes of mothers of low birth weight babies - a comparison of ethnic groups in East London, UK. Matern Child Nutr 1, 91-99.

24. Irles Rocamora JA, Iglesias Bravo EM, Aviles MS, Bernal LE, de Valle Galindo PB, Moriones LL, Maetzu AA \& Mingo CD (2003) Nutritional value of the diet in healthy pregnant women. Results of a nutrition survey of pregnant women. Nutr Hosp 18, 248-252.

25. Jacobs DR, Pereira MA, Meyer KA \& Kushi LH (2000) Fiber from whole grains, but not refined grains, is inversely associated with all-cause mortality in older women: the
Iowa women's health study. J Am Coll Nutr 19, Suppl. 3, 326S-330S

26. Trumbo P, Schlicker S, Yates AA \& Poos M (2002) Dietary reference intakes for energy, carbohydrate, fiber, fat, fatty acids, cholesterol, protein and amino acids. J Am Diet Assoc 102, 1621-1630.

27. Watts V, Rockett H, Baer H, Leppert J \& Colditz G (2007) Assessing diet quality in a population of low-income pregnant women, a comparison between Native Americans and whites. Matern Child Health J 11, 127-136.

28. Mai V, Flood A, Peters U, Lacey JV Jr, Schairer C \& Schatzkin A (2003) Dietary fibre and risk of colorectal cancer in the Breast Cancer Detection Demonstration Project (BCDDP) follow-up cohort. Int J Epidemiol 32, 234-239.

29. Institute of Medicine (1990) Nutrition During Pregnancy. Washington, DC: National Academy Press.

30. Sichieri R \& Everhart JE (1998) Validity of a Brazilian food frequency questionnaire against dietary recalls and estimated energy intake. Nutr Res 18, 1649-1659.

31. Giacomello A, Schmidt M, Nunes MA, Duncan B, Soares R, Manzolli P \& Camey S (2008) Validade de questionário de freqüência alimentar, relativa a recordatório, para uso em gestantes. Rev Bras Saúde Materno Infantil (In the Press).

32. Philippi ST (2002) Tabela de Composição de Alimentos: Suporte para Decisão Nutricional, 2nd ed. São Paulo: Coronário.

33. Departamento de Alimentos e Nutrição Experimental da Faculdade de Ciências Farmacêuticas - USP (2001) Tabela Brasileira de Composição de Alimentos. http://www. fcf.usp.br/tabela2007 (accessed August 2007).

34. Cho S, Devries JW \& Prosky L (1997) Dietary Fiber Analysis and Applications. Gaithersburg, MD: AOAC International.

35. Li BW \& Cardozo MS (1992) Nonenzymatic-gravimetric determination of total fiber in fruits and vegetables. J $A O A C$ Int 75, 372-374.

36. Beaton GH (2006) When is an individual an individual versus a member of a group? An issue in the application of the dietary reference intakes. Nutr Rev 64, 211-225.

37. Murphy SP, Guenther PM \& Kretsch MJ (2006) Using the dietary reference intakes to assess intakes of groups: pitfalls to avoid. J Am Diet Assoc 106, 1550-1553.

38. Heaton KW (1973) Food fibre as an obstacle to energy intake. Lancet 2, 1418-1421.

39. Castro MB, Kac G \& Sichieri R (2006) Padrão de consumo alimentar em mulheres no pós-parto atendidas em um centro municipal de saúde do Rio de Janeiro, Brasil. Cad Saude Publica 22, 1159-1170.

40. Kac G (2001) Determinant factors of postpartum weight retention: a literature review. Cad Saude Publica 17, 455-466.

41. Nielsen JN, Gittelsohn J, Anliker J \& O’Brien K (2006) Interventions to improve diet and weight gain among pregnant adolescents and recommendations for future research. J Am Diet Assoc 106, 1825-1840.

42. Polley BA, Wing RR \& Sims CJ (2002) Randomized controlled trial to prevent excessive weight gain in pregnant women. Int J Obes Relat Metab Disord 26, 1494-1502.

43. Instituto Brasileiro de Geografia e Estatística (2004) Pesquisa de Orçamentos Familiares 2002-2003. Rio de Janeiro: IBGE.

44. Murtaugh MA, Jacobs DR Jr, Jacob B, Steffen LM \& Marquart L (2003) Epidemiological support for the protection of whole grains against diabetes. Proc Nutr Soc 62, 143-149.

45. Arkkola T, Uusitalo U, Pietikainen M, Metsala J, KronbergKippila C, Erkkola M, Veijola R, Knip M, Virtanen SM \& Ovaskainen ML (2006) Dietary intake and use of dietary supplements in relation to demographic variables among pregnant Finnish women. Br J Nutr 96, 913-920. 